Florida International University FIU Digital Commons

7-10-1992

\title{
Test-retest reliability and synchronous status of heart rate recorded in vivo in children with phobic disorder
}

Alexander J. Chapunoff
Florida International University

DOI: $10.25148 /$ etd.FI14060145

Follow this and additional works at: https://digitalcommons.fiu.edu/etd

Part of the Psychology Commons

\section{Recommended Citation}

Chapunoff, Alexander J., "Test-retest reliability and synchronous status of heart rate recorded in vivo in children with phobic disorder" (1992). FIU Electronic Theses and Dissertations. 2113.

https://digitalcommons.fiu.edu/etd/2113 
ABSTRACT OF THE THESIS

Test-Retest Reliability and synchronous status of Heart Rate Recorded In Vivo in Children with Phobic Disorder by

\author{
Alexander $\mathrm{J}$. Chapunoff \\ Florida International University, 1992 \\ Miami, Florida \\ Professor Wendy K. Silverman, Major Professor
}

The present study assesses the synchrony and test-retest reliability of the three fear response systems in clinically diagnosed phobic disordered (experimental subjects) and nonphobic children (controls). Subjects (five boys and one girl, aged seven to sixteen, in each group) underwent three in vivo phobic assessments, each including a measure of self-report of fear (subjective), degree and duration of approach (behavioral) and heart rate (physiological), resulting in a total of 36 assessments. Synchrony coefficients for both groups indicated low inter-relationships among the systems. Test-retest coefficients of heart rate indicated moderate-to-very high reliability, with reliability being somewhat higher for phobics. Test-retest coefficients of the subjective and behavioral measures indicated high reliability for both groups, particularly the controls. Implications of the results are discussed with respect to the synchrony and assessment of the response systems. Future 
(ABSTRACT OF THE THESIS, continued)

research directions are delineated. 
Test-Retest Reliability and Synchronous status of Heart Rate Recorded In Vivo in Children with Phobic Disorder

A thesis submitted in partial satisfaction of the requirements for the degree of Master of science in Psychology

by

Alexander J. Chapunoff 
(C) Copyright by

Alexander $J$. Chapunoff

1992 
To Professors: Luis A. Escovar

William M. Kurtines

Wendy K. Silverman

This thesis, having been approved in respect to form and mechanical execution, is referred to you for judgment upon its substantial merit.

Dean Arthur Herriott

College of Arts and Sciences

The thesis of Alexander J. Chapunoff is approved.

Luis A. Escovar

William M. Kurtines

Wendy K. Silverman,

Major Professor

Date of Examination: July 10, 1992.

Dean Richard Campbell

Division of Graduate Studies

Florida International University, 1992 


\section{ACKNOWLEDGMENTS}

I would like to thank all of the subjects who participated in this study, particularly the control subjects and their mothers. I am also grateful to the students who repeatedly participated as observers.

I also thank Dr. Luis A. Escovar and Dr. William M. Kurtines for their insight and suggestions, both of which improved the study and made it renderable.

Special thanks go to Dr. Wendy K. Silverman for all her guidance and for having provided me with the opportunity to learn so much. 
LIST OF TABLES......................... vi

LIST OF FIGURES.............................. vii

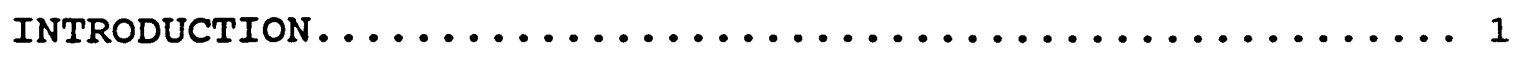

THE TRIPARTITE MODEL OF FEAR AND ANXIETY........... 5

DESYNCHRONY AND THE TRIPARTITE MODEL.............. 9

THE RELIABILITY OF HEART RATE MEASURES............. 14

Adult Literature........................ 15

Children's Literature.................... 16

The Holden and Barlow study.................. 18

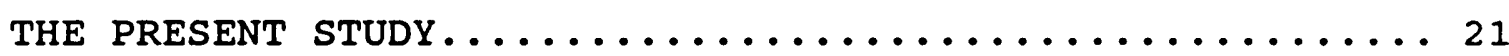

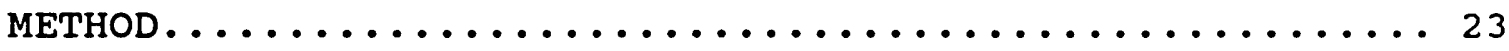

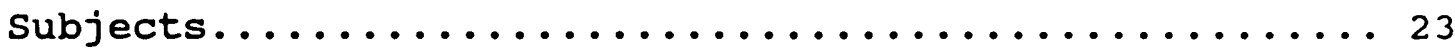

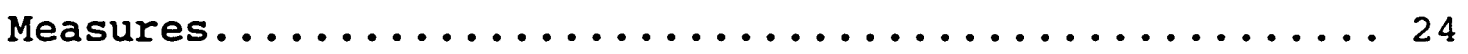

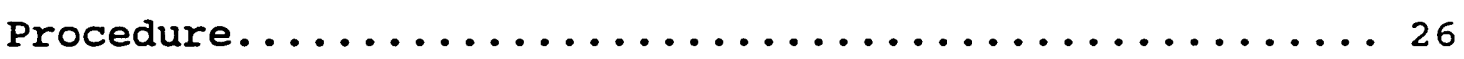

Analytical and statistical statement............ 29

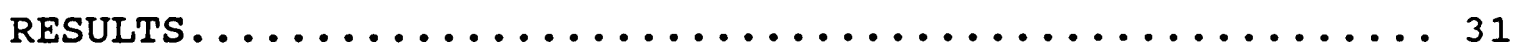

Mean Response Component Data......................... 31

synchronous status...................... 34

Patterns of Experimental and Control Subjects' Response

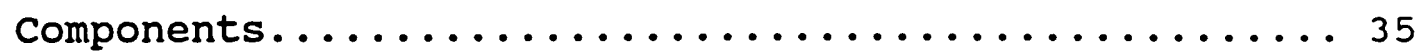

Test-Retest Reliability.................. 37

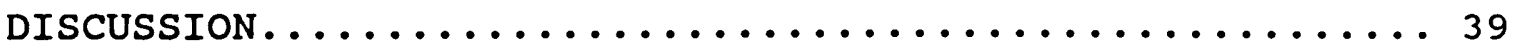

Mean Response Component Data.................... 41

synchronous status......................... 44 
Test-Retest Reliability...................... 45

summary and Future Directions...................46 TABLES AND FIGURES.............................. 52

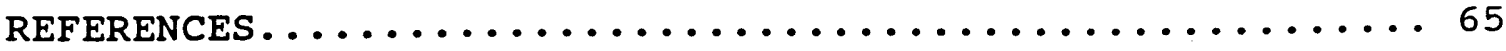

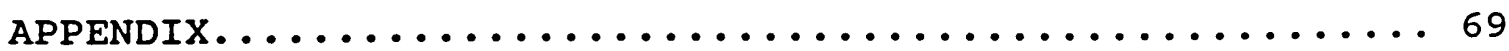


Table

Page

1. Characteristics of Experimental and Control Subjects on a Matched Pair Basis........... 52

2. Correlations Among the Three Response Components for Experimental and Control subjects....... 59

3. Fear Thermometer, BAT and Heart Rate Scores for the Experimental and Control Subjects Across the Three Assessment Sessions............. 60

4. Test-Retest Reliability Coefficients of the Three Heart Rate Scores for the Experimental and

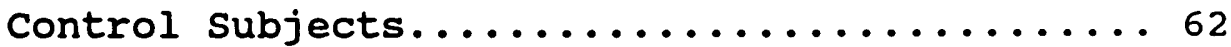

5. Test-Retest Reliability Coefficients of the Three Fear Thermometer scores for the Experimental and

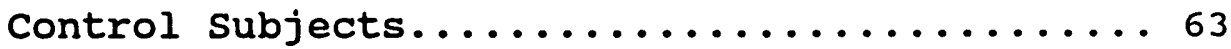

6. Test-Retest Reliability Coefficients of the Three BAT Scores for the Experimental and Control subjects............................ 64 
Figure

Page

1. Mean Heart Rate for Experimental and Control

Subjects Across the Three Assessment

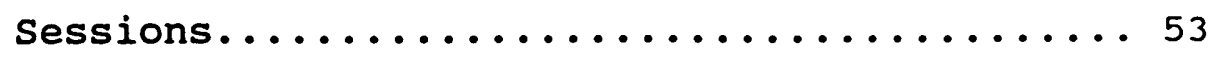

2. Mean Heart Rate for Experimental and Control

Subjects (Excluding subject Pair \#2) Across the

Three Assessment sessions............... 54

3. Mean Fear Thermometer Ratings of Experimental and

Control Subjects Across the Three Assessment

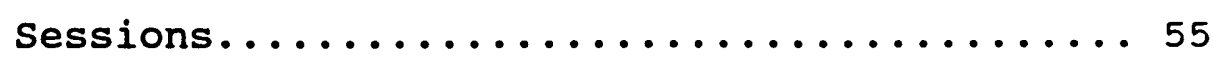

4. Mean BAT Scores of Experimental and control

Subjects Across the Three Assessment

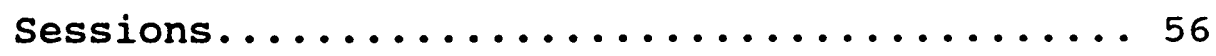

5. Difference Scores of Experimental and Control

Subjects Across the Three Assessment

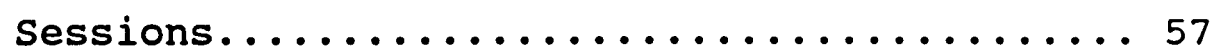

6. Difference Scores of Experimental and Control

Subjects (Excluding subject Pair \#2) Across

the Three Assessment Sessions............ 58 
Test-Retest Reliability and Synchronous status of Heart Rate

Recorded In Vivo in Children with Phobic Disorder

since ancient times, man has sought to understand the relationship between the mind and the body. This curiosity to unravel the mysteries of psychophysiology is spurred by the hope that it will be discovered which physiological variables indicate the presence of, and differentiate between, various psychological variables (Ray \& Raczynski, 1981).

Although the concept of psychophysiology dates back to antiquity (Burdick, 1978; Ray \& Raczynski, 1981), it is only in relatively recent times that modern technology has rendered feasible the possibility of accurately monitoring the relationship(s) between the mind and the body, or to use more contemporary jargon, between the cognitive (or subjective) and physiological response systems. After all, the assessment of such indices as heart rate, vasomotor activity, and skin conductance in naturalistic settings requires a sophistication which has only recently been made available (Ray \& Raczynski, 1981).

However, researchers such as Lang (1977) have shown that the mind/body dichotomy is incomplete; rather, mind, body, and behavior contain their own properties which may or may not interact at any given point. The degree of correlation between the cognitive, physiological, and behavioral response systems is termed "synchrony" (when they correlate) or 
"desynchrony" (when they do not).

Support for this tripartite, or three-systems, approach is considerable (e.g. Barlow, Mavissakalian, \& Schofield, 1980; Beidel, Turner, \& Dancu, 1985; Hodgson \& Rachman, 1974; Lang, 1977, etc.). Few would argue against the desirability of such an encompassing and thorough assessment. However, if the original goal of researchers was to seek that elusive correlation or covariation between systems, that goal has begun to give way to a more realistic and obtainable one: Because the notion of synchrony (both between and within systems) has consistently been controversial in the scientific literature, the goal has become "the study of the parameters under which each of the components may independently be affected" (Hugdahl, 1981, p. 86). In other words, each of the three components may or may not correlate or covary with one or two of the others -because each is, by nature, complex and affected by many variables. For instance, Burdick (1978) cites several studies (e.g. Bellet, 1963; Norman \& Melville, 1972; see Burdick, 1978) indicating that heart rate can be affected by many extra-psychological factors such as metabolic rate, exercise, nutrition, physical position, age, gender, body temperature and size, etc. One begins to see that what Barlow, Mavissakalian, and Schofield (1980) called the "long-standing [therapeutic] assumption" (p. 447) of a generalization among the three response components is 
tenuous and variable.

That the systems do not always correlate does not mean their study should be neglected; on the contrary, this is cause for further empirical investigation. Many questions remain unanswered: In what types of subjects do all or some of the systems correlate or covary? And under what circumstances? And, regardless of its synchronous status, how is each system affected?

Naturally, it is in the study and treatment of the anxiety and phobic disorders that this knowledge and its value can be acquired and appreciated. Psychophysiologic responses are an integral part of anxiety (Beidel et al., 1985; Lang, 1977). These "anxiety responses" are typically recognized as affecting the three response components in disorders from social anxiety in adults (Beidel et al., 1985) to simple phobia and overanxious disorder in children (Silverman \& Nelles, 1990; Silverman \& Eisen, in press).

Given, then, that psychophysiology plays an important role in the anxiety and phobic disorders it follows that the implications, clinically, are large: by being better acquainted with the relationship(s) (if any) between physiology and the cognitive and behavioral domains, a therapist can have a more knowing and insightful indication of a patient's overall status. For instance, if the research evidence suggests that it is typical for child agoraphobics to have a significantly accelerated pulse rate, 
together with, say, a high self-report of fear and a low amount of avoidance behavior during an in-vivo exposure to their fearful stimulus then a therapist who saw such a pattern in a given patient could more assuredly deduce that patient's actual clinical condition.

Empirically, how is physiology assessed in relation to psychology? Although there are many measures (e.g. heart rate, blood pressure, epinephrine, electromyograph, palmar sweat, galvanic skin response, etc.), heart rate is the most commonly used, probably because it is technologically feasible (Holden \& Barlow, 1986) as well as convenient and accessible. This pragmatic raison d'etre is counterbalanced by a common interest in the relationship between heart activity and emotional state that has aroused curiosity since the time of the ancient Greeks (Burdick, 1978). However, although some researchers (e.g. Watson, Gaind, \& Marks, 1972) have found heart rate to be a useful measure of response to phobic stimulation in phobic subjects, others (e.g. Holden \& Barlow, 1986) have found heart rate to have low reliability when it comes to assessing phobic stimulation.

It is important to clarify the issue of the reliability of heart rate measurement not only because heart rate is the most commonly used physiological measure but also because the issue of its reliability becomes inextricably intertwined with the issue of synchrony. In other words, of what 
value is it to obtain information on the degree of intersynchronicity between the physiologic, cognitive, and behavioral systems if the physiologic (heart rate) is unreliable?

of equal consideration is the issue of in whom these systems are being measured and compared. Is it the same to speak of, for instance, synchrony in simple phobic children as in agoraphobic adults? Unfortunately, while the psychophysiological literature on anxious or fearful adults is scant, the literature on children is truly infinitessimal (Beidel, 1988, 1989).

Nevertheless, the following evaluation of the literature available on the three-systems model, desynchrony, and the reliability of heart rate -- in different anxious and phobic subject types -- will help clarify which aspects of psychophysiological assessment require further study. Thus, I begin with a further elaboration of the tripartite model of fear and anxiety.

The Tripartite Model of Fear and Anxiety

As indicated above, most contemporary anxiety researchers assess anxiety according to three response systems: subjective/cognitive (self-report), behavioral, or physiological (Barlow, 1985; see Abelson \& Curtis, 1989). Thus it can be, and often is, inferred that physiologic reactivity may be a valid indicator of the presence of fear, phobia, or anxiety. However, in his tripartite model, Lang (1977) proposed that 
each of the above three response systems is able to occur either alone or in combination with any or both of the other two. Hugdahl (1981) opined that the tripartite (or, as it is sometimes known, the three-systems) model implies that fear is not a single system or entity but a group of partially independent components. In explaining why they are "independent" (because of low intercorrelations), Hugdahl (1981) stated that the above-mentioned conception of fear or anxiety as a group of components is more important than stressing the covariance or dissociation between the components because this conception will help provide a new way of looking at the nature of fear and anxiety itself. Although it may be true that fear is composed of these three partially independent systems, the possible patterns of synchrony should not be de-emphasized. Granted, the research has proven to be polemic, with some studies showing correlations (Grey, Sartory, \& Rachman, 1979; Marzillier, Carroll, \& Newland, 1979; Watson et al., 1972) and others not (Abelson \& Curtis, 1989; Barlow, Mavissakalian, \& Schofield, 1980; Craske, Sanderson, \& Barlow, 1987), but this may be at least partially explained by the fact that important methodological differences across studies exist, including subject, design, and task differences.

Nevertheless, the fact that the three systems are not always "in synch" should not come as a surprise to anyone acquainted with Lang's (1977) model. The problem is not 
that subjective and behavioral measures of fear and anxiety do not always correlate with physiologic measures--Lang's research had already indicated that synchrony may or may not exist. The difficulty, rather, lies in being able to reliably assess in what specific types of circumstances and in what specific types of individuals the presence of physiologic responses will correlate with the presence of the other two response types.

Lang (1977) provided support for this notion that it is important to study when and in whom synchrony exists. He wrote, "the central task of theorists is to provide us with guiding, explanatory constructs, models or analogies which organize these data, and ultimately provide a basis for practical prediction and control" (Lang, 1977, p. 9).

The literature is by no means clear or concise in obtaining this degree of "practical prediction and control." It is difficult to say exactly why the correlation between the three systems is so variable. Theoretically, the tripartite approach itself is a heuristic vision of fear, realistically accounting for its three principal components. Practically, however, the wide methodological differences across experimenters have contributed to a wide spectrum of results. One problem may be that different researchers use different types of physiologic indicators. Because desynchrony among various physiological measures and indices has been demonstrated (Abelson \& Curtis, 1989), this makes it 
difficult to tell how applicable certain results are. In other words, if heart rate does not covary with palmar sweat, then how could knowing of palmar sweat's synchrony with, say, avoidance behavior indicate anything about heart rate's synchrony with avoidance behavior?

Then there is the possibility that the synchronous status of the three systems has no clinical significance at all. Barlow, Mavissakalian, and Schofield (1980) found no relationship between desynchrony and clinical improvement in agoraphobic women. Similarly, Craske, Sanderson, and Barlow (1987) found no significant relationship between the followup status of agoraphobic women and the desynchrony between heart rate and subjective measures of fear. Although in both studies high heart rate itself was associated with treatment responsiveness, particularly in Craske et al.'s (1987) study. (See next section for further discussion.)

on the other hand, Grey, Sartory, and Rachman (1979) found no differences in the clinical improvement of highheart rate responders and low-heart rate responders in a population of simple phobic adults; they did find that heart rate and self-reported fear synchronized in subjects who improved. Also studying simple phobics, Watson, Gaind, and Marks (1972) likewise found that physiological improvement paralleled clinical improvement; in other words, heart rate decreased as subjects improved. There was concordance between the systems but not precise synchrony -- physio- 
logical, cognitive, and behavioral changes accompanied each other, but at different rates.

The patterns described in the above studies indicate a difference between agoraphobic and simple phobic patients. This seems to reinforce the notion that the investigation of the three systems -- how each varies in and of itself and how all interrelate -- is a complex and multifaceted phenomenon that is complicated further still by a possible variance across different patient populations. Now that the tripartite model in general has been elaborated upon, a discussion focusing on desynchrony specifically among the three systems follows below. Desynchrony and the Tripartite Model

Discussing the three-systems model and not discussing desynchrony is akin to talking about apples and oranges without talking about fruit. In a sense, the fact that the three systems have been delineated and separated into distinct "partially independent" entities is itself a testament to desynchrony: for if they always synchronized they would effectively be a single, unitary system, something that Lang (1977) argued was unrealistic. As a matter of fact, Lang (1977) noted that desynchrony among the response systems is the rule, not the exception, in psychopathology.

The value of studying the synchronous status of the three response systems is that it provides a more thorough and in- 
depth analysis of any given individual. As Hodgson and Rachman (1974) stated, "...the degree of synchrony provides important clues about the processes involved and more practically, therapeutic interventions can be considered fully satisfactory only if neurotic responses are eliminated across cognitive, behavioral and physiological systems" ( $p$. 322).

But if the original goal of the research -- finding a correlation or covariation between the systems -- has given way to a new goal -- finding when and in whom the systems tend to correlate, covary, or not; and how each system does on its own -- then what of the trends garnered so far from the existing literature?

As indicated earlier, Craske et al. (1987) found absolute heart rate to be more strongly related to treatment responsiveness than synchrony between heart rate and selfreport measures of fear. Subjects with high heart rates were more responsive to treatment than low-heart rate subjects. However, the presence of low heart rate or desynchrony "did not preclude the possibility of treatment success" (Craske et al., 1987, p. 121). Craske et al. (1987) interpreted their results as supporting Lang's (1979; see craske et al., 1987) notion that physiological arousal is predictive of a positive treatment outcome "because it signals the processing of fear, which is necessary for fear reduction" (p. 122). In other words, nonresponders had 
lower heart rates not so much because they avoided the fear stimulus (approach behavior did not distinguish responders from nonresponders) but because of an inherent lack of "willingness to approach and tolerate the feared situation even at pre-assessment" (p. 122). These findings indicate a state of desynchrony between the cognitive and physiological systems (high self-report of fear, low heart rate or, conversely, low self-report of fear, high heart rate) which, as mentioned above, in and of itself was not significantly related to treatment responsiveness.

That this desynchrony was unrelated to treatment responsiveness is no accident. The cognitively fearful subjects had lower heart rates because they did not process the phobic situation sufficiently. Otherwise, their heart rates could have skyrocketed. Only when full psychological exposure to the stimulus occurs should heart rate be fairly considered; if not, it could result in a misleading desynchrony.

These results also bring to mind Hugdahl's (1981) statement that it is the "cognitive labelling and attribution of the perceived [physiological] arousal" (p. 77) that determines the cognitive or behavioral reaction. Likewise, Beidel et al. (1985), in a study assessing the three-systems aspects of social anxiety, determined that "the discriminating factor might be that they [non-anxious subjects] do not experience concomitant cognitive distress 
or label this arousal as 'anxiety' as do the socially anxious" (p. 110).

This explanation of the weight that the cognitive component may carry in relation to the physiological and behavioral components is interesting, especially from a clinical point of view since it can give a therapist a focal point to work on. Nevertheless, it does not help explain the typical lack of specific patterns across the research investigations that have studied desynchrony.

Nesse et al. (1985), realizing that a significant amount of the prior research had been limited by a difficulty in "reliably inducing severe and sustained stress in human subjects in a laboratory setting" (p. 320), decided that in vivo exposure therapy for adult simple (animal) phobics would help remove those limitations, reasoning that induced subject anxiety in such a procedure would be high. Indeed, a self-report measure, Subjective Units of Distress (SUDS), demonstrated that elicited anxiety was severe during treatment. However, although the exposures resulted in significant increases in such physiologic measures as pulse, blood pressure, plasma norepinephrine, epinephrine, insulin, cortisol and growth hormone, the general results were complicated and difficult to interpret. Nesse et al. (1985) found that "the magnitude... and concordance of endocrine and cardiovascular responses showed considerable variation" ( $p$. 320) despite the fact that the subjective (SUDS) and 
behavioral (experimenter observation of agitation, tremors, crying, etc.) components of anxiety were high. Thus, this study is a prime example of desynchrony, showing how the physiological component does not always manifest simultaneously with the subjective and the behavioral. The study was conducted with adults (women) and it remains to be seen whether a replication with other types of subjects would yield similar findings.

Abelson and Curtis (1989) assessed desynchrony among the three major response types in two adult, male height phobics over the course of a behavioral treatment. Treatment proved effective for both subjects but desynchrony was considerable. As a matter of fact, heart rate and SUDS were often inversely related. Both subjects overcame their phobia and were still doing well at 6- and 8-month follow-ups (Abelson \& Curtis, 1989). This success in treating the phobia led the authors to suggest that "synchrony among all three systems is not necessary for successful treatment of a phobia or for preservation of gains at follow-up" (Abelson \& Curtis, 1989, p. 565).

In addition to the pronounced desynchrony observed between systems (i.e. cognitive, behavioral and physiological), however, there was also desynchrony observed within the physiological response system itself (e.g. heart rate, norepinephrine level). Abelson and Curtis (1989) state that the physiological reaction system is "not a 
unitary system but a complex web of systems" (p. 567). Further, they offer that the same may be true for the subjective/cognitive and behavioral response components (Ohman, 1987; see Abelson \& Curtis, 1989).

Finding consistent relationships between the three response systems does not necessarily mean finding more synchrony. Instead, it means discovering any inter- and intra-system patterns that may exist in a) certain diagnostic categories and b) under certain circumstances (for instance, when exposed to various stimuli in different settings; imaginal versus in-vivo, etc.). To have a valid indication of how each component tends to respond under many combinations of circumstances (subject type and task, for example) is to have a practical advantage because this knowledge can provide a practitioner with a detailed profile of a patient's psychophysiological status. Whether such knowledge can first be reliably obtained is a question which remains to be empirically answered, however. It is this issue of reliability that I turn to next. The Reliability of Heart Rate Measures

In the study of psychophysiology, as is apparent from the discussion thus far, it is important to have a common index to represent the physiological component in the comparison to the psychological traits being studied. As mentioned earlier, heart rate seems to be the measure of choice among researchers because it is easy to assess and is the least 
sensitive to measurement artifacts (Nietzel \& Bernstein, 1981; see Ollendick \& Francis, 1988). In addition to being technologically feasible (Holden \& Barlow, 1986) there is some preliminary evidence, albeit uneven, indicating that it can be used to predict treatment outcome in anxious patients (Ost, Jerremalm, \& Johansson, 1981; see Holden \& Barlow, 1986).

Adult Literature. By some accounts, heart rate reliably assesses the body's response to fear or anxiety. Watson et al. (1972), in a study assessing heart rate and skin conductance measures across an exposure-based treatment for simple phobics, upon finding that both heart rate and skin conductance habituated steadily to the identical phobic exposures, concluded that "heart rate is a useful measure of response to intense imaginal and real [simple] phobic stimulation" (p. 277).

on the other hand, there is the view that any single physiological measure cannot provide a reliable indication of psychological arousal. Lang (1977) argued that because intercorrelations among the physiological measures are very low, any response patterns garnered from a single measure may be random and basically meaningless, from a psychological point of view. Therefore, multiple assessments would be necessary to obtain a "consensual estimate of overall reactivity" (p. 29).

Marzillier, Carroll, and Newland (1979), in a series of 
imaginal sessions, found that simple (snake) phobics reported increasing anxiety and demonstrated cardiac acceleration in the earlier as well as later trials. Nonphobics, however, reported progressively less fear over trials and a corresponding reduction in cardiac acceleration -- from acceleration to biphasic heart response (deceleration preceding acceleration). Moreover, there were no differences found between groups on the skin conductance measures, indicating that, at least in this study, heart rate was the more reliable measure. Holden and Barlow (1986) studied the test-retest reliability of heart rate recorded in-vivo in a group of agoraphobic women undergoing treatment while exposed to their phobic stimulus (walking a specific course towards a downtown area) and compared those measures with controls'. Their analysis indicated that test-retest reliability for both groups of subjects was low. (Holden and Barlow's (1986) study is discussed in greater detail below.)

Children's Literature. Due to developmental differences between children and adults, it is unwise to generalize research results obtained with adult subjects to child subjects. Unfortunately, however, the amount of research on psychophysiological assessment with children having anxiety or phobic disorders is very thin. Further, the problem with interpreting studies that were conducted prior to 1980 is two-fold. First, the recent advent of new technologies has 
made it possible to monitor and assess changes in the physiologic responses of phobics and controls in more realistic, and emotion inducing, situations (Holden \& Barlow, 1986). Second, with the appearance of the DSM-III and in 1987 of the DSM-III-R, the inclusion of childhood anxiety disorders has served to increase the reliability and specificity of assessment by providing a template of diagnostic criteria for researchers to follow.

Unfortunately, only one study has been conducted to date that has assessed heart rate in DSM-III-R diagnosed cases of anxiety-disordered children, and that is Beidel (1988). Beidel (1988) assessed elementary school children with clinically significant test anxiety who engaged in two social-evaluative tasks: a timed vocabulary test and an oral reading session. The children's heart rates were monitored during both tasks. Anxious children were found to have significantly larger heart rate changes and higher heart rates than the nonanxious controls in both tasks. Beidel (1988) interpreted these results as an indication that testanxious children's anxiety may not be limited to test situations and, indeed, may "spill over" to other socialevaluative situations, because heart rate responses were similar across both conditions. Interestingly, Beidel (1988) noted that the "autonomic responsivity of these anxious children bears some resemblance to that of socially anxious adults" (p. 81). These findings suggest that heart 
rate is a valid measure of test anxiety but, of course, do not comment on the relation to other anxiety or phobic disorders. The author's comparison of the anxious subjects to socially anxious adults gives promise to the possibility that psychophysiological responsivity characteristics may be generalizable across the lifespan.

Given the scarcity of heart rate data on DSM-III-R diagnosed children, it is important to obtain further data on this population. The Holden and Barlow (1986) study is exemplary of the type of research that needs to be conducted and for this reason is discussed in some detail below.

The Holden and Barlow study. Holden and Barlow's (1986) study comparing female adult agoraphobic and female adult nonphobic control subjects' heart rates across a 12-week treatment program attempted to assess the usefulness of heart rate as a psychophysiological measure in a clinically. diagnosed population. The study found that although agoraphobics had significantly higher heart rates, as well as greater heart rate lability, test-retest reliability for both groups was low. Subjects were assessed three times (each time from one to nine days apart) before treatment began, once at the midpoint of the therapy program, and three times (again, from one to nine days apart) after the treatment ended. These were in vivo behavioral assessments during which heart rate was monitored. The test consisted of walking a given course from the treatment center toward a 
downtown area.

The agoraphobic subjects reported a significant decrease in anxiety, as measured by SUDS, across treatment along with a decrease in heart rate. Unexpectedly, however, the nonphobic control subjects' heart rates also decreased significantly. At no point did they report any anxiety. The finding that the test-retest reliability coefficients for both groups were so low raises questions about the usefulness of heart rate as a physiologic measure, at least in agoraphobics. The authors point out, however, that "the apparent lack of usefulness of heart rate as a measure of change in agoraphobics may not be true for some focal or simple phobias" (Holden \& Barlow, 1986, p. 38). They cite a couple of Lang studies (Lang, 1985; McNeil, Melamed, Guthbert, \& Lang, 1983) where marked differences were found in the "physiological responsiveness to phobic imagery in focal phobics who 'responded' to fearful imagery whereas agoraphobics did not" (Holden \& Barlow, 1986, p. 38). While conceding that there are dissimilarities between imagery assessments and in vivo assessments, Holden and Barlow (1986) maintain that "the lack of responsiveness of agoraphobics when directly compared to normals in the same situation seems similar" (p. 38).

However, the nonphobics' responsiveness to the physiological assessment procedures seems to be the key issue here. The problem in Holden and Barlow's (1986) study was 
not the agoraphobics' "unresponsiveness"; indeed, their initially high and labile heart rates (higher and more labile than the nonphobic controls') decreased over treatment, as did their self-reports of fear/anxiety. The fact that everyone responded in the latter fashion -- in other words, both phobics and nonphobics demonstrated corresponding decreases in heart rates -- indicates that heart rate may not have much discriminant validity.

Given the lack of significant differences in the heart rate decreases of phobics and nonphobics, Holden and Barlow (1986) speculated why the nonphobics' heart rates were higher in the earlier assessments: novelty effects, the nature of the task itself (e.g. speaking into a hidden microphone in public to report anxious state, wearing strange equipment next to skin, etc.) and performance anxiety were all offered as possibilities. None of these reasons are specific to nonphobic subjects, however, and could just as well explain the elicitation of anxiety in the phobic subjects. Also important is to note that at no point in the assessment procedure did the controls report any anxiety .

In summary, the review of the literature has indicated, first, the importance of establishing whether heart rate can be reliably measured in children with anxiety or phobic disorders, a population which has been understudied to date; second, it has indicated the importance of establishing to 
what degree heart rate synchronizes with the other two response systems in such a population.

\section{The Present study}

The present study assesses the test-retest reliability of heart rate measurement in children with phobic disorder. In addition, the degree of synchrony (or desynchrony) among the three response systems is examined.

Due to the acknowledged paucity of psychophysiologic studies dealing with clinically phobic and anxietydisordered children (Beidel, 1989), the present study assessed clinical subjects whose inclusion and participation in the study were based on a diagnostic interview (Anxiety Disorders Interview Schedule for Children Revised; Silverman \& Nelles, 1988) using DSM-III-R criteria for Phobic Disorders. Although it may have been preferable to include only one phobic disorder (e.g. simple phobia), practical constraints rendered this difficult. Therefore, children who met the criteria for either simple or social phobia were included in the study.

The present study is a partial replication of Holden and Barlow's (1986) study. The principal modification is the just-mentioned difference in experimental subject type (phobic disordered children instead of agoraphobic women), and that test-retest reliability is measured across the pretreatment phase only.

As the review of the literature indicated, research on 
heart rate assessment in phobic disordered children is very scarce; nor is there much research in the adult literature. For this reason, precise predictions with respect to the study's results are difficult to make. Based on Beidel's (1988) results, one might expect that heart rate assessment would be reliable. On the other hand, based on Holden and Barlow's (1986) results (i.e. the moderate test-retest coefficients combined with the suggestion that differences between the phobic and control subjects' heart rate responses were clinically insignificant), one might expect low reliability.

The possibility of subject age affecting psychophysiology contributes to the difficulty in predicting this study's results. For example, it has been hypothesized that child subjects would show greater desynchrony than adult subjects because the relatively less developed language skills could impede an accurate self-analysis and self-report on the part of the subject (Lang, 1977). However, the simple five-point fear thermometer scale used in this study (see "Method" section) was intended to compensate for this by not requiring the use of any advanced linguistic or communication skills.

The contribution of this investigation is that it is the first to examine how the three-response system correlates in simple and social phobic children who are confronting their phobic stimulus. It is also the first to examine the 
reliability of the heart rate response as a clinical index in these types of phobic disordered children.

\section{Method}

\section{Subjects}

Experimental subjects consisted of six phobic-disordered children: five boys and one girl. Ages ranged from 7 years 4 months to 16 years 10 months (the mean age for the phobics was 11 years 10 months; mean age for controls was 12 years one month; see Table 1 for a description of the subjects.) Four of the subjects were diagnosed as social phobics and two as simple phobics (one height and one dog phobic) via the Anxiety Disorders Interview Schedule Revised (Silverman \& Nelles, 1988). This interview has been found to have adequate interrater (Silverman \& Nelles, 1988) and testretest reliability (Silverman \& Eisen, 1992). Children were interviewed with the Child version (ADIS-C) and parents with the Parent version (ADIS-P). Inclusion in the study was based on a composite diagnosis. (See Appendix for instructions on derivation of the composite diagnosis.)

The experimental sample was composed of children whose parents contacted the Child Anxiety and Phobia Program (CAPP) at Florida International University, University Park because they perceived difficulties in their children's lives due to the children's anxious or fearful behavior. Self-referred parents and children heard of the program through the media; other families were referred by school 
psychologists or school counselors.

Each experimental subject was matched to a nonphobic control with respect to gender and age (a maximum of one year age difference was allowed). Four of the six control subjects were recruited from among persons living in the experimenter's neighborhood, one was the sibling of a CAPP client (this CAPP client did not participate in the present study) and one was the friend of a CAPP client. Each control subject was paid $\$ 10$ per assessment session, for a total of $\$ 30$. Each control was interviewed with the social Phobia, Simple Phobia, and Agoraphobia sections of the Anxiety Disorders Interview Schedule, Child version (ADIS-C) prior to inclusion in the study to ensure the absence of any clinically significant phobias. No control subject met criteria for any of these disorders.

Measures

Subjective/self-report measures. During the BAT's in vivo exposure, each subject's subjective reports were obtained using a 1 to 5-point Fear Thermometer scale. This consisted of showing the child a sheet of paper depicting five thermometers with the accompanying labels: "not at all", "a little", "somewhat", "pretty much", and "very much"; as the fear rating increases, each thermometer is pictured as becoming progressively "hotter." Every child was asked once a minute, for a maximum of five minutes, to rate their fear on this scale. The Fear Thermometer scale 
is useful in that it simplifies the rating task for children and removes some of the variability attributed to language skills that occurs when young children respond to questionnaires (Barrios, Hartmann, \& Shigetomi, 1981).

Behavioral measures. The in vivo behavioral task that each phobic was asked to perform was the same as the day-today fear- or anxiety-provoking task that brought the child to seek treatment. For example, the dog phobic had to approach a real dog, the height phobic was required to climb onto a roof with a ladder, the social phobics had to unscramble words on a blackboard before a small audience. Each task lasted a maximum of five minutes. During the simple phobic in vivo exposures (BATs), the degree of approach (in feet) toward the phobic object was recorded on a minute-by-minute basis for the duration of the test -- for the purposes of analysis, this variable was coded as either "no approach" (1), "partial approach" (2) or "complete approach" (3). Duration of time (in minutes) that the subject could perform the task was also recorded. During the social phobic in vivo exposures, the behavioral measure was duration of time the subject spent in front of the audience -- for the purposes of analysis, this variable was coded as either "no exposure" (1), "partial exposure" (2) or "complete exposure" (3).

Physiological measures. To monitor heart rate across the session, a UNIQ Heartwatch was attached to each subject 
prior to each assessment. The UNIQ Heartwatch consists of a transmitter that is strapped to the subject's chest and of a wristwatch receiver that is attached to the subject's wrist.

After the assessment session, the UNIQ Heartwatch was removed from the subject and the data obtained from the wristwatch receiver. For each assessment session's six phases (adaptation, baseline, walking or standing baseline, BAT exposure, post-walking or -standing baseline, and postbaseline), the fifteen-second mark into each phase was used as the mean heart rate for that phase.

\section{Procedure}

After the experimental subjects were determined appropriate for the study by being diagnosed as having a phobic disorder, they and their parent(s) were contacted to schedule a consultation. This consisted of explaining the assessments and the treatment program to the child and his or her parent(s).

After the consultation, a Behavioral Approach Task (BAT) was conducted during which the child was to ultimately approach his or her feared stimulus. This was the first of three such pretreatment assessment sessions -- each with the same procedure.

Prior to the BAT's in vivo exposure, there were an adaptation period, a baseline period, and a walking baseline period.

The five-minute adaptation phase consisted of the child 
sitting alone in a room at the clinic with instructions that he or she shouldn't walk around but rather should remain seated and perhaps read a magazine. Self-report fear ratings were obtained precisely at the beginning and end of the five-minute period.

The baseline constituted the next five-minute phase and contained the same instructions for the child. Fear ratings were obtained precisely at the beginning of the period, at the 1-minute and 3-minute points and precisely at the end of the phase (the 5-minute point).

The standing or walking baseline occured next during which the child and session administrator either stood next to a blackboard -- with the child drawing or writing on the board -- or walked about the halls of the CAPP at a regular, moderate pace. The standing baseline was utilized for social phobics and the walking baseline for simple phobics, as the social phobics had to stand and the simple phobics had to walk, respectively, during their BATs. Fear ratings were obtained at the same intervals as during the baseline. Upon completion of the walking or standing baseline, the in vivo exposure test (BAT) was conducted. Self-report fear ratings were obtained once a minute from the subject.

All the social phobia BATs were characterized by each subject's being given five words to unscramble on a blackboard in front of a group of three to five onlookers who were personally unknown to the subject. The fifteen- 
and sixteen-year-old subjects unscrambled six-letter words whereas the seven- and eight-year-old subjects unscrambled four-letter words. In the event that a subject solved the scrambled words before the five-minute time period, a list of extra words was used, so that all subjects spent the entire phase in solving the task. Because in the social phobia task physical approach towards the stimulus was not a factor, the behavioral component was assessed only by noting whether or not the subject left the BAT prematurely.

The simple phobia BATs consisted of one height phobia task and one dog phobia task. For the former, a six-foothigh ladder was placed adjacent to the outside of the CAPP wall and each subject was instructed to climb the ladder as high as he could and also, if possible, climb onto the roof and remain there for as long as he felt he could. For the latter, each subject was asked to approach a Lhasa Apso dog which stood thirty-three feet away, at the other end of the CAPP's center hall.

For the two simple phobia tasks, the behavioral component was assessed by measuring the amount of feet which each subject approached the phobic stimulus. This was recorded on a minute-by-minute basis. It was also noted whether or not the subject left the BAT prematurely.

After the in vivo exposure test, there were a five-minute post-test walking or standing baseline phase and a fiveminute post-test baseline phase, identical in procedure to 
the baseline and walking/standing baseline phases mentioned above.

Heart rate was monitored throughout all the phases for each subject (see "Physiological measures" above for more details).

All six phobics and their six matched counterparts underwent the three BAT assessments, rendering a total of 36 assessment sessions. In all matched cases, identical tasks and stimuli were used.

Also matched for each subject pair was the interval time between assessment sessions 1 and 2 and assessment sessions 2 and 3. The interval time between assessments ranged from one to seventeen days, with the average interval time being 8.25 days. The most modal interval time was 7 days. Analytical and Statistical statement

For each and every of the three in vivo BAT sessions, the following measures were obtained for each experimental and control subject:

1. For the cognitive/subjective response system, the mean fear/anxiety reported by subjects on the fear thermometer scale.

2. For the behavioral response system, social phobia BATs assessed whether a subject refused to confront the stimulus at all (thus receiving a 1 value), left prematurely (thus receiving a 2 value) or confronted the stimulus for the entire phase (thus receiving a value of 3 ). The simple 
phobia BATs assessed the mean degree (in feet) as well as the duration of approach of subjects. Here, subjects who refused to approach at all were scored a 1, those who approached the stimulus incompletely were scored a 2 , and those who fully approached the stimulus were scored a 3 .

3. For the physiological response system, the mean heart rate of subjects.

The above measures were examined for each subject individually as well as for each group (experimental versus control). The difference score between the post-test walking or standing baseline and the BAT, was also assessed. According to Holden and Barlow (1986), this measure "controls for the myriad of other factors that might be influencing heart rate that day and isolates the effect of the [task] itself" (p. 35).

The issue of synchrony/desynchrony is explored in a preliminary fashion as well. Specifically, intercorrelations were computed between each subject group's mean subjective (self-report ratings), behavioral (BAT), and physiological (heart rate) data.

To assess the test-retest reliability of the heart rates, reliability (correlation) coefficients were calculated between each of the three BAT assessment sessions (between assessments 1 and 2 , between assessments 1 and 3 and between assessments 2 and 3 ) for all the experimental and control subjects. Reliability coefficients were likewise calculated 
for the self-report and behavioral measures.

\section{Results}

The results obtained from the present study are reported in three sections. First, the means and standard deviations of each of the response systems for both the phobic and control subjects, respectively, are presented. The difference scores between the standing or walking baseline heart rate and the BAT heart rate of both groups are also given. Second, the inter-correlations among the three systems are presented for both the phobic and control subject groups to assess the synchronous status of these response components. Each individual subject's data for the three systems are also presented along with his/her control subject counterpart's data. Third, the test-retest reliability coefficients for the heart rate scores are presented. Reliability coefficients for the fear thermometer and BAT scores are also included.

\section{Mean Response Component Data}

The phobic and control subject groups' mean heart rate data are presented in Figure 1. The figure indicates that the control group's mean heart rates were higher, across the three BAT assessments, than the phobics'. For BAT assessment \#1, phobics' mean heart rate was lower than the controls' $(\underline{m}=94.83, \underline{s d}=16.47 ; \underline{m}=99.67, \underline{s d}=20.16$, respectively). Despite this initial discrepancy, the difference in heart rate means decreased at BAT assessment 
\#2 (phobics: $\underline{m}=100.00, \underline{s d}=13.34 ;$ controls: $\underline{m}=103.33$, $\underline{s d}=27.88$ ) and disappeared at the time of BAT \#3 (phobics: $\underline{m}=100.67, \underline{s d}=11.36 ;$ controls: $\underline{m}=100.83, \underline{s d}=18.98)$.

It should be pointed out that were it not for control subject \#2's (height phobia task, male, age 16) unusually high heart rates, the controls' mean heart rates would have been consistently lower than the phobics' mean heart rates. Control subject \#2's high heart rates during the BAT were due to the fact that he fully performed the physically strenuous approach (climbing onto a trailer roof) while the phobic did not. (This point is elaborated upon in the "Discussion" section.)

Indeed, upon excluding subject pair \#2 from the mean heart rate calculations, a different pattern across the three assessment sessions emerges. As Figure 2 indicates, at assessment \#1, the phobics' mean heart rate was slightly higher than the controls' $(\underline{m}=94.00, \underline{s d}=18.28 ; \underline{m}=93.20$, $\underline{s d}=13.94$, respectively). For the second assessment the difference between both subject groups' means increased (phobics: $\underline{m}=98.80, \underline{s d}=14.46 ;$ controls: $\underline{m}=93.00, \underline{s d}=$ 13.06) and was maintained at BAT assessment \#3 (phobics: $\underline{m}=$ $98.40, \underline{\mathrm{sd}}=11.08 ;$ controls: $\underline{m}=93.80, \underline{\mathrm{sd}}=8.90)$.

Experimental subjects had higher mean fear thermometer scores across all three assessments $(\underline{m}=2.33, \underline{s d}=1.25$; $\underline{m}=1.97, \underline{s d}=1.19 ; \underline{m}=1.95, \underline{s d}=1.27$ ) than the control subjects $(\underline{m}=1.11, \underline{s d}=.27 ; \underline{m}=1.11, \underline{s d}=.27 ; \underline{m}=1.0$, 
$\underline{\text { sd }}=0$ ) (see Figure 3 ). There was little within-subjects variance in fear thermometer scores across the three assessments (with half of the subjects scoring 1.0 across all three sessions; the most notable exception is phobic \#1 (social phobia, male, age 16), whose self-report fear ratings decreased from 3.33 on his first assessment to 1.0 on his third.

As Figure 4 indicates, experimental subjects had slightly lower mean BAT scores across the three assessments (phobics: $\underline{m}=2.67, \underline{s d}=.52 ; \underline{m}=2.83, \underline{s d}=.41 ; \underline{m}=2.67, \underline{s d}=.52 ;$ controls: $\underline{m}=2.83, \underline{s d}=.41 ; \underline{m}=3.0, \underline{s d}=0 ; \underline{m}=3.0$, $\underline{\text { sd }}=0$ ), which indicates a slightly higher degree of approach behavior. Only two subjects showed any withinsubjects variance in their behavioral approach: phobic subject \#3 (dog phobia, female, age 7), who fully approached her fearful stimulus only on BAT assessment \#2 and control subject \#2 who fully approached the fearful stimulus only on BAT assessments \#2 and \#3.

The difference scores between the standing or walking baseline heart rate and the BAT heart rate are depicted in Figure 5. These scores show that the controls had a considerably smaller response than the phobics across the three assessments. This indicates that the BAT elicited higher heart rates in the control group than in the phobic group. As with the mean heart rate calculations, however, control subject \#2's elevated heart rates during the BAT 
skewed the results. Thus, Figure 6 depicts the difference scores with subject pair \#2's data excluded.

Figure 6 indicates that, without the influence of subject pair \#2, only during the first assessment session was the controls' difference score lower -- indicating, at this point, their greater heart rate response to the properties of the BAT relative to the phobics' heart rate response. At BAT \#2 there is almost no discrepancy between the difference scores of both groups. By BAT \#3 the experimental subjects' lower difference score indicates that now their heart rates responded more to the approach task than the control subjects' heart rates.

\section{Synchronous status}

To determine the extent of synchrony among the three response systems, correlations among the three components were calculated. These appear in Table 2 for both the experimental and control subjects. None of these correlations were statistically significant at the .05 or .10 levels of significance.

Results in Table 2 show that, for both experimental and control subject groups, there were relatively high negative correlations between BAT scores and heart rate (phobics: $\underline{r}=-.72$, controls: $\underline{r}=-.94)$ and lower negative correlations between BAT scores and fear thermometer ratings (phobics: $\underline{\underline{r}}=-.55$, controls: $\underline{\underline{r}}=-.21$ ). There was a moderate positive correlation between heart rate and fear 
thermometer ratings for phobics $(\underline{\underline{y}}=.66)$; for controls the correlation between these two components was a low negative one $(\underline{r}=-.17)$.

\section{Patterns of Experimental and Control Subjects' Response}

\section{Components}

Each subject's data for the three response systems was individually listed, across the three assessments, to compare: a) each response component's patterns in relation to the other two and b) each experimental subject's data with his or her control counterpart's data (see Table 3). overall, an examination of each subject pair's heart rates indicates that the only discernible trend is that, in every pair, the heart rate patterns tend to converge by the time of the third BAT assessment.

Subject Pair \#1 (social phobia, male, age 16). Overall, the differences between phobic and control are that the control's heart rates were higher and the phobic's fear thermometer ratings were higher in assessments 1 and 2 , before decreasing in assessment 3 to the control's level. BAT scores were identical and constant across the three assessments for both subjects.

Subject Pair \#2 (height phobia, male, age 16). Here, a couple of differences are apparent. The control subject's heart rate is higher than the experimental subject's. However, as mentioned before, this was due to the physical exertion characteristic of this BAT's full approach, as the 
control fully approached and confronted the phobic stimulus whereas the phobic did not. The phobic subject had higher self-report ratings than the control subject.

Subject Pair \#3 (dog phobia; female; phobic--age 7, control--age 8). For this pair, the phobic's heart rate and self-report ratings were considerably higher than the control's. Also, the phobic fully approached her stimulus only once (during BAT 2), whereas the control did so all three times.

Subject Pair \#4 (social phobia, male, age 15). The only difference between this pair is that the control subject's heart rate started out considerably higher than the phobic's for BAT 1 and then decreased so that by BAT 3 it was somewhat lower than the phobic's. The phobic's heart rate decreased only slightly from BAT 1 to BAT 2 and increased a bit from BAT 2 to BAT 3 so that by BAT 3 it was a little higher than its initial (BAT 1) score. BAT and fear thermometer scores were identical and constant across the three assessments for each subject.

Subject Pair \#5 (social phobia; male; phobic--age 8 , control--age 7). For this pair there was a similar pattern of heart rate as that noted in subject Pair \#4. The phobic's heart rate during BAT 1 was considerably lower than his control counterpart's. BY BAT 3 it was somewhat higher. The phobic's fear thermometer ratings were slightly higher than the control's. BAT scores were identical and constant 
across the three assessments for each subject.

Subject Pair \#6 (social phobia; male; phobic--age 7, control--age 8). The only difference in scores between both subjects in this pair was in heart rates. During BATs 1 and 2 the phobic showed higher heart rates; by BAT 3, though, both subjects' heart rates were practically identical. This is due to the fact that, from assessment \#2 to assessment \#3, the control's heart rate increased a total of $19 \mathrm{~b} . \mathrm{p} . \mathrm{m}$. compared with the phobic's decrease of 4 b.p.m. BAT and fear thermometer scores were identical and constant across the three assessments for both subjects.

\section{Test-Retest Reliability}

To assess the test-retest reliability of the heart rate measures, correlations were computed between the mean heart rate scores across the first and second, first and third, and second and third BAT assessments. These appear in Table 4 for the experimental and control subjects.

As can be seen from Table 4 , both subject groups showed similar patterns in their correlation coefficients: a moderate positive correlation between the mean heart rate scores of BATs 1 and 2 (phobics: $\underline{r}=.83$, controls: $\underline{r}=$ .77), a somewhat lower positive correlation between the mean heart rates of BATs 1 and 3 (phobics: $\underline{r}=.77$, controls: $\underline{r}=$ .65) and the highest positive correlation between BATs 2 and 3 (phobics: $\underline{\underline{r}}=.94$, controls: $\underline{r}=.91$ ). In each case, the experimental subject group showed higher correlations. None 
of these correlations were statistically significant at the .05 or .10 levels.

The test-retest reliability of the fear thermometer scores was also assessed. These coefficients are presented in Table 5. As the table indicates, for the phobic subjects the same pattern of relatively high positive correlations was found as in the heart rate test-retest coefficients: Between assessments 1 and 2 , an intermediate correlation $(\underline{r}=.88) ;$ between assessments 1 and 3 , the lowest correlation $(\underline{\underline{r}}=.71)$; and between assessments 2 and 3 , the highest correlation $(\underline{\underline{r}}=.92)$. For the control subjects, test-retest coefficients were positive and extremely high: Between assessments 1 and $2(\underline{r}=1.0)$, between assessments 1 and $3(\underline{r}=.99)$, and between assessments 2 and $3(\underline{r}=.99)$. The control subjects' coefficients were statistically significant $(\underline{p}<.05)$ while the phobic subjects' test-retest coefficients were not statistically significant.

For the BAT scores (see Table 6) the phobics showed moderate positive correlations between assessments 1 and 2 $(\underline{\underline{r}}=.63)$ and between assessments 2 and $3(\underline{\underline{r}}=.63)$; between assessments 1 and 3 there was a perfect positive correlation $(\underline{r}=1.0)$. Only the last of these correlations was statistically significant $(\underline{p}<.05)$; the first two were not. As with the fear thermometer coefficients, the control subjects showed a pattern of extremely high positive correlations: Between assessments 2 and $3(\underline{\underline{r}}=1.0)$, 
between assessments 1 and $2(\underline{r}=.99)$, and between assessments 1 and $3(\underline{r}=.99)$. These coefficients were all statistically significant $(\underline{p}<.05)$.

\section{Discussion}

Although preliminary in nature, the present study is important in that it is the first to assess the test-retest reliability and synchronous status of heart rate in simple and social phobic children who were carefully diagnosed along DSM-III-R criteria. overall, the results indicate a pattern of greater responsiveness to in vivo fear exposures on the part of phobic subjects when compared to nonphobic controls across the three response systems of fear and anxiety (i.e. the physiological, the subjective and the behavioral). With respect to the physiological response system, the phobics' mean heart rate response was greater than the nonphobics'. In addition, the phobics' difference scores indicated that they progressively increased their heart rate response during the in vivo exposure whereas the nonphobics progressively decreased their response. (The difference score is the measure which, by subtracting the BAT heart rate from the standing or walking post-baseline heart rate, isolates the influence of the BAT task on the subject's BAT heart rate.) similarly, the phobics' higher fear thermometer scores indicated that their response was greater than the nonphobics' within the subjective response component. Lastly, the phobics' lower mean BAT scores 
indicated their greater response within the behavioral component.

Although not significant, the synchrony patterns among the three response components revealed high negative correlations between heart rate scores and BAT scores and low negative correlations between BAT scores and fear thermometer scores for both phobic and control subjects. The synchrony patterns between heart rate scores and fear thermometer scores revealed a moderate correlation for the phobic subjects and a very low negative correlation for the control subjects.

Test-retest reliability coefficients of heart rate scores revealed moderately high correlations between assessments 1 and 2, moderate correlations between assessments 1 and 3 and very high correlations between assessments 2 and 3 for both phobic and control subjects. In each instance the correlation was somewhat higher for the phobic subjects.

The phobics' test-retest coefficients of fear thermometer scores revealed the same pattern of correlations as the heart rate test-retest coefficients; namely, moderately high between assessments 1 and 2 , moderate between assessments 1 and 3 , and very high between assessments 2 and 3 .

Test-retest reliability coefficients for BAT scores indicated moderate correlations between assessment sessions 1 and 2 and between assessment sessions 2 and 3 for the phobic subjects; between assessment sessions 1 and 3 the 
coefficients indicated a perfect correlation for this subject group. Test-retest coefficients of the BAT scores indicated extremely high significant correlations for the control subjects.

\section{Mean Response Component Data}

Mean Heart Rate and Difference Scores. Although, as mentioned above, the response systems appeared more responsive to the in vivo phobic stimuli within the phobic subject group, mean heart rate requires more careful attention than the other two response systems due to control subject \#2's (height phobia task, male, age 16) unusually elevated heart rate data.

When including subject pair \#2's data, the mean heart rate and difference score results are inconsistent with both subject groups' respective statuses (i.e. "patient" versus "control") -- inconsistent because one would expect the phobic subjects' or "patients'" heart rates to respond more to a phobic exposure than the nonphobic subjects' or controls' heart rates. However, due to the physically strenuous nature of the height phobia BAT -- which control subject \#2 fully performed while his phobic counterpart did not -- control subject \#2's heart rate acceleration is more indicative of physical exertion than of a psychophysiological response to fear.

There may also be an additional measurement artifact involved. The fact that the first 15-second interval of the 
BAT phase was used to represent the entire phase's mean heart rate magnified control subject \#2's physical exertion as it was in the very beginning of the BAT phase that the control subject approached the stimulus (the first 15 to 20 seconds). Indeed, when calculating control \#2's mean heart rate for the first BAT by averaging all the 15-second intervals which recorded his heart rate, his mean heart rate is 88.48 instead of 132 , which was only the first 15-second interval that the heartwatch recorded.

Thus, only when subject pair \#2's data are excluded from the mean heart rate and difference score calculations do these measures indicate the pattern suggestive of the phobic subjects' greater response to the in vivo fearful stimulus. This finding is similar to Holden and Barlow's (1986), who also found control subjects' mean heart rates to be lower and more stable across the three assessments than phobic subjects'. However, the difference in heart rates between the phobic and control subjects in the present study was less than the difference found between the groups in the Holden and Barlow (1986) study.

Fear Thermometer Ratings. Consistent with their respective clinical statuses (i.e. "patient" versus "control"), phobic subjects (or "patients") had higher mean fear thermometer ratings across the three assessments than the control subjects. Similar to the agoraphobics in the Holden and Barlow (1986) study, the simple and social child phobics 
in the present study showed a slight decrease in their selfreports of fear across the first three (pre-treatment) assessments, although their self-reports of fear were consistently higher than the control subjects'. These findings are consistent as well with those of Marzillier et al. (1979), who also found that phobics had higher selfreport fear scores than nonphobics. Specifically, Marzillier et al. (1979) found that adult snake phobics reported more fear than nonphobic controls during 15 imaginal phobic tasks. However, contrary to Holden and Barlow's (1986) and the present study's control subjects, who reported the minimal fear rating across all assessment sessions, Marzillier et al.'s (1979) control subjects initially reported a relatively high fear rating (almost as high as the phobic subjects). The extent to which exposure sessions are conducted imaginally (as in Marzillier et al., 1979) or are conducted in vivo (as in Holden \& Barlow, 1986 and the present study) may result in different response patterns on the part of subjects requires further clarification.

BAT (Approach) Scores. The present study's results indicate that the controls had slightly higher approach scores than the phobics, across the three assessments. Interestingly, the phobics' mean BAT scores improved at assessment \#2, compared with assessment \#1; however, at assessment \#3 they returned to the initial level. On the 
other hand, the controls' BAT scores improved slightly on each successive assessment. Because these differences were small, it would be premature at this time to make too much out of them. However, one might speculate that perhaps the phobics were not as able as the controls to habituate to the BAT's fear-inducing qualities.

\section{Synchronous status}

The analysis of the synchrony coefficients obtained in the present study supports the notion that each response system may just as easily indicate a phobic response alone as it might in combination with one or both of the remaining systems. Lang's (1977) notion that the subjective and behavioral measures of fear and anxiety do not always correlate with the physiological measure, then, is further supported by the present study.

It would thus appear that, as is commonly affirmed in the literature, synchrony among the three response components remains the exception, not the rule. Hugdahl (1981) indicated that low intercorrelations made the three systems "partially independent" from one another. Lang (1977) argued that, though synchrony was unrealistic, the importance of studying it was to detect any existent patterns (i.e. however synchronous or desynchronous they may be) and thus provide clinicians a basis for "practical prediction and control" (p. 9). Due to the small sample size, however, the present study does not reveal any 
patterns containing specific clinical implications. Nevertheless, the investigation and analysis of the link between synchrony and reliability in a child phobic sample, as presented here for the first time, may serve as a useful launching pad for future investigations studying these constructs.

\section{Test-Retest Reliability}

The test-retest reliability coefficients of both the phobic and control subjects indicated comparable patterns: an intermediate correlation between the mean heart rate scores of BATs 1 and 2 (phobics: $\underline{r}=.83$, controls: $\underline{r}=$ .77), a lower correlation between the mean heart rates of BATs 1 and 3 (phobics: $\underline{r}=.77$, controls: $\underline{r}=.65$ ) and the highest correlation between BATs 2 and 3 (phobics: $\underline{r}=.94$, controls: $\underline{r}=.91$ ).

These results indicate that heart rate measures in in vivo phobic exposures are fairly consistent and that, specifically, they are slightly more consistent for phobic child subjects than for nonphobic child subjects. This reliability is encouraging in that it suggests that heart rate can be a dependable measure. Evidently, the presence of a phobia only slightly affects the test-retest reliability of heart rate.

In Holden and Barlow's (1986) study, the test-retest reliability coefficients for the three pretreatment assessments were equally moderate for both subject groups 
(phobics: $\underline{\underline{r}}=.63$, controls: $\underline{\underline{r}}=.64$ ). Future reliability studies that include the various phobic categories as well as different age groups would be helpful to establish any significant differences in reliability as a function of these subject characteristics. It would also be helpful to perform a study that could investigate the different subject types with the same empirical design so as to eliminate the confound of task and design differences across studies.

Test-retest coefficients for the fear thermometer scores indicated that this subjective measure was as reliable for the phobics as the heart rate scores. For the controls it had very high reliability. The test-retest coefficients for the BAT scores indicated moderate-to-high correlations for the phobics and very high correlations for the controls.

This greater consistency on the part of the control subjects may underline the relative ease with which these subjects tolerated the in vivo exposure. The fact that they consistently self-reported the lowest fear rating and fully approached the stimulus supports this notion.

\section{Summary and Future Directions}

In summary, the present study is an important first step in assessing the test-retest reliability of heart rate and the synchrony between the three response systems in DSM-IIIR diagnosed simple and social phobic children.

Previous studies had assessed the reliability of heart rate in adult agoraphobics (e.g. Holden \& Barlow, 1986) and 
in test-anxious children (e.g. Beidel et al., 1991) but had neglected its role within the context of the three systems. On the other hand, some researchers assessed the relationships among the three systems in adult agoraphobics (e.g. Craske et al., 1986; Mavissakalian \& Michelson, 1981) and socially anxious adults (Beidel et al., 1985) but neglected to study the reliability of the measures used.

Although the generalizability of the present study's findings is limited, the results do suggest that simple/ social phobic and nonphobic children will score consistently with their respective clinical statuses on heart rate, selfreport fear thermometer and BAT measures. They also suggest that the test-retest reliability of heart rate is somewhat higher for simple/social phobic children than it is for nonphobic children. On the other hand, for the fear thermometer and BAT measures used in this study, the testretest reliability was somewhat higher for the nonphobic children.

There are several limitations of the present study that should be noted. First is the small sample size $(\underline{n}=6)$. With a larger sample, some of the correlations might have been significant. Coupled with the small sample, is the small amount of variance observed within some of the response systems (particularly the fear thermometer and BAT scores). Thus, caution is warranted with respect to interpreting the present study's obtained correlations. The 
small sample size also hinders a more detailed investigation of the various phobic categories. As noted earlier, with a large sample, the reliability and synchrony of the three systems might be investigated in the social phobic, agoraphobic and (diverse) simple phobic categories while also concentrating on gender and age differences within, and across, those diagnostic groups. However, with the present study, the requirement that each subject be assessed three times, on three separate ocassions, made it difficult to obtain a larger sample; this particularly encumbered the commitment of control subjects. It should also be pointed out that although the sample size is relatively small, in fact each subject underwent three separate assessment sessions, resulting in a total of 36 observations. Moreover, Abelson and Curtis (1989) assessed desynchrony among the three response systems in only two subjects and Holden and Barlow's (1986) agoraphobic sample was comprised of only ten subjects. Perhaps the small samples studied in these investigations underscore the practical difficulties in this type of research. But, of course, it will be important for future research to overcome these difficulties and include larger samples in work of this kind.

A second limitation of the present study is that, with the exception of subject pair \#5, the experimental subjects and their matched control counterparts were not assessed under identical circumstances. Due to practical 
constraints, controls were often assessed at different times of day and days of the week than their phobic counterparts; also, the interval times between assessment sessions were generally not identical between matched subjects. And in the case of the social phobia assessment sessions, although the same number of observers was used for the experimental and control subjects' in vivo tasks, often they were different individual observers -- of different ages and gender. Another potential confound is that, due to the difficulty of obtaining control subjects to participate in three assessment sessions, all of the controls were not recruited in an identical fashion. It is suggested that future researchers control confounds between the matched phobic and control subjects as well as within those respective subject groups. This would include, of course, same time and date of assessments as well as identical experimenters, stimuli and recruitment method.

The problems inherent to using the self-report measure, especially in regards to the control subjects, could also be considered a limitation. While it is certainly feasible that the controls felt no fear or anxiety (as judged by their uniformly very low self-reports and high degree of approach during the BAT), it is also possible that they self-reported lower fear ratings in order to be consistent with their "roles" as non-phobics (i.e. "look good" for some demand that they not respond phobically). 
Regarding the validity of the BAT, it is possible that, as a behavioral index, it is too gross and general a measure to capture any subtleties or minor discrepancies inherent to the subjects' approach behaviors. By only considering three possibilities in the social phobic (no exposure, partial exposure, and complete sustained exposure) and simple phobic tasks (no approach, partial approach, and complete approach), the BAT measure never assessed other qualitative behavioral characteristics such as subjects' facial expressions, body language, or voice quality. An assessment of these characteristics, in addition to gauging the degree of exposure or approach (as was done in the present study), would provide a more detailed and informative portrait of the behavioral component and its status than the general BAT measure alone would. Beidel et al. (1991) employed such a behavioral assessment. In their study investigating the three-systems aspects of social anxiety in adults, Beidel et al. videotaped each subject's performance. The behaviors in these videotapes were rated by independent raters on 5-point qualitative scales that included such characteristics as intonation, speech loudness and gaze. Anxiety was rated separately on a 9-point scale.

Future investigations that assess the reliability and synchrony of the three systems in anxious and phobic children and that account for the present study's limitations will hopefully be able to determine the above points 
more definitively.

As the psychophysiological properties of anxious and phobic children are constructs of heuristic and clinical relevance and because little light has been shed on them to date, their continued empirical investigation should be advocated. To this end, the present study has helped synthesize and underline those areas of importance to such future investigation. 
Table 1

Characteristics of Experimental and control subjects on a

Matched Pair Basis

Experimental subjects

Control subjects

Phobia, Gender, Age

Gender, Age

Pair 1 social, male, 16 yrs. 4 mos. male, 16 yrs. 10 mos.

Pair 2 height, male, 16 yrs. 4 mos. male, 16 yrs. 1 mo.

Pair 3 dog, female, 7 yrs. 10 mos. female, 8 yrs. 6 mos.

Pair 4 social, male, 15 yrs. 4 mos. male, 15 yrs. 2 mos.

Pair 5 social, male, 8 yrs. 5 mos. male, 7 yrs. 4 mos.

Pair 6 social, male, 7 yrs. 4 mos. male, 8 yrs. 11 mos. 
Figure 1

Mean Heart Rate for Experimental and control subjects Across the Three Assessment Sessions

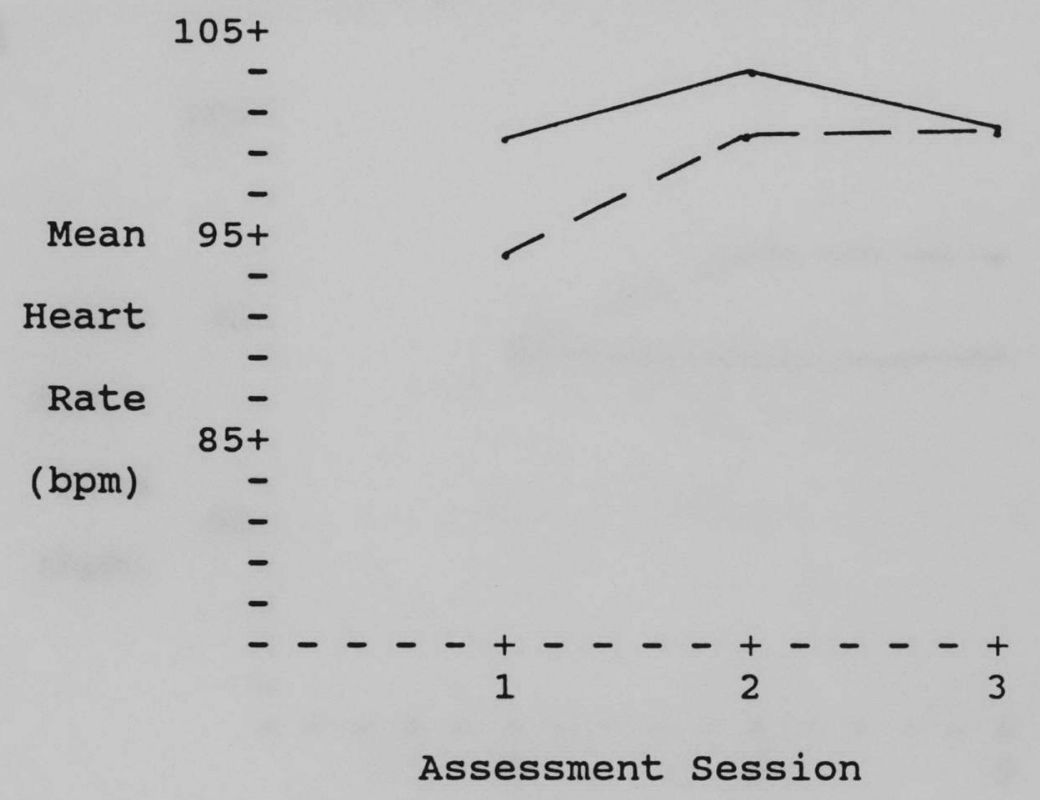

Experimental subjects - - - -

Control subjects 
Figure 2

Mean Heart Rate for Experimental and Control subjects

(Excluding Subject Pair \#2) Across the Three Assessment Sessions

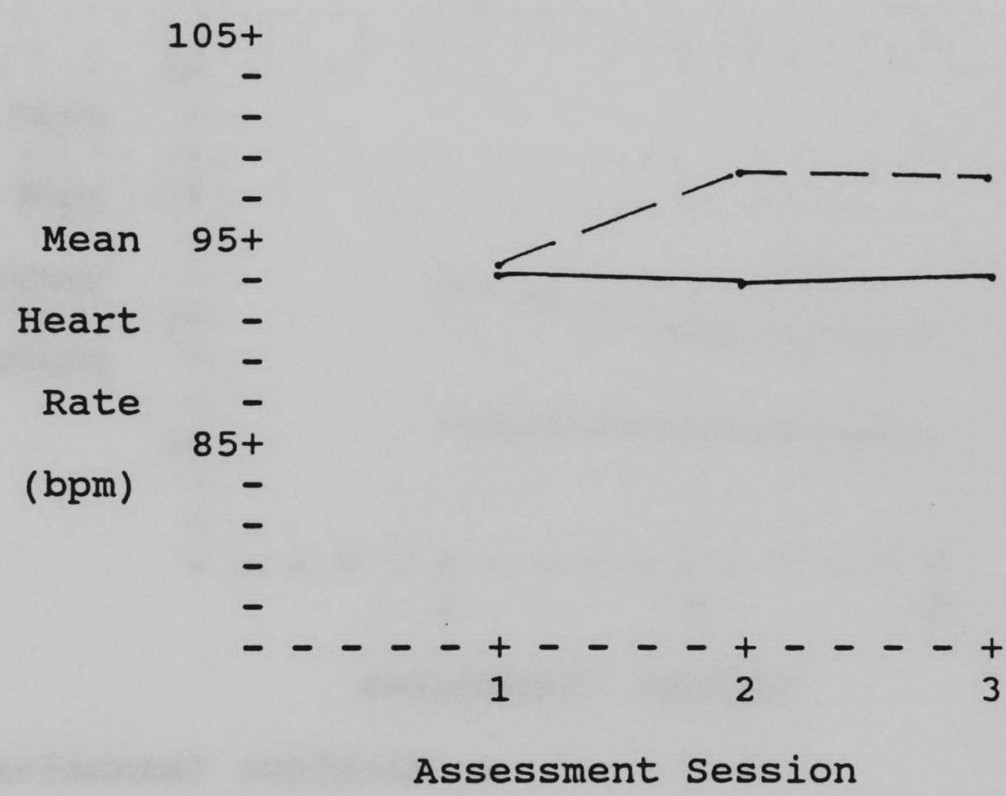

Experimental subjects - - - -

Control subjects 
Figure 3

Mean Fear Thermometer Ratings of Experimental and Control

Subjects Across the Three Assessment Sessions

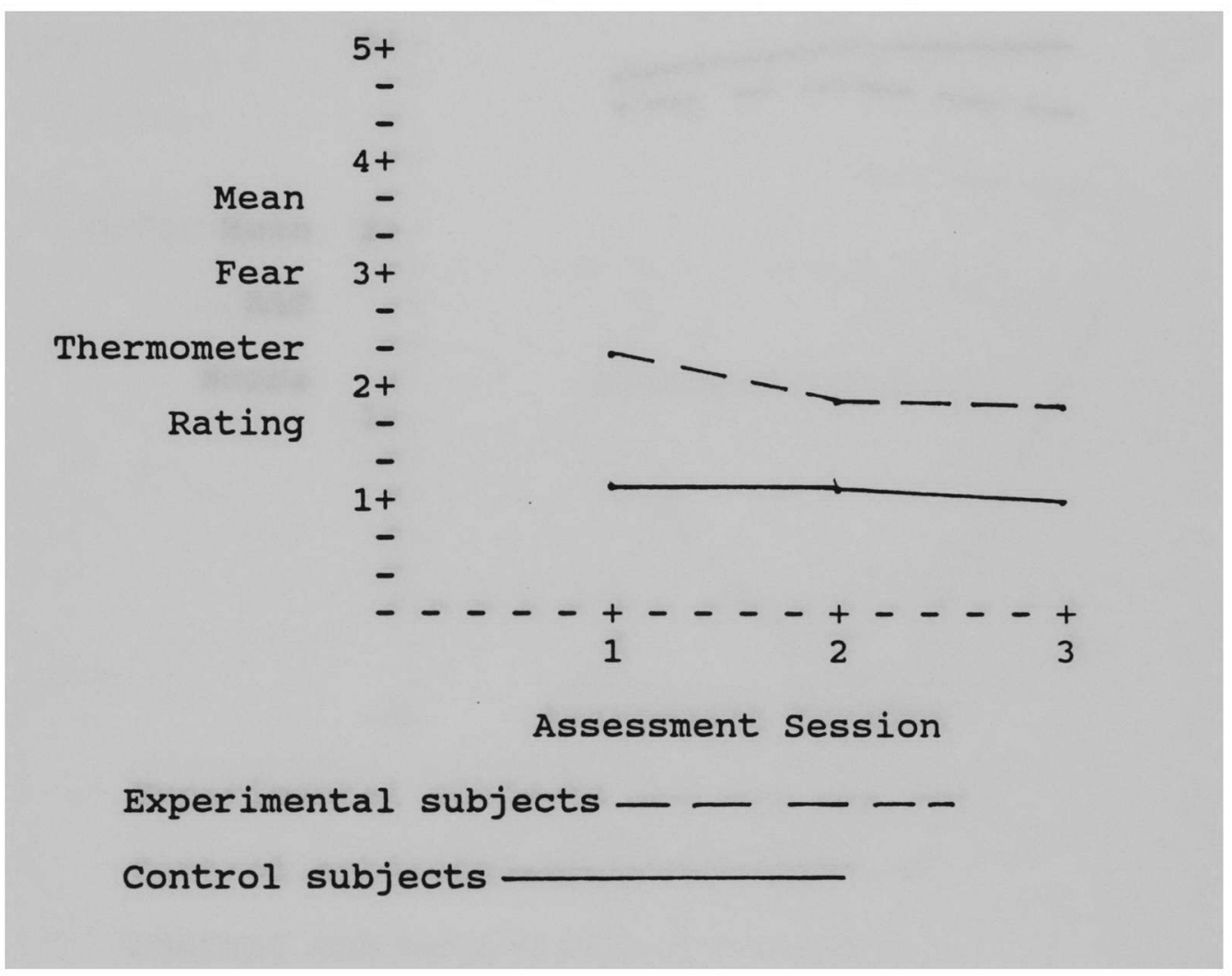


Figure 4

Mean BAT Scores of Experimental and control subjects Across the Three Assessment Sessions

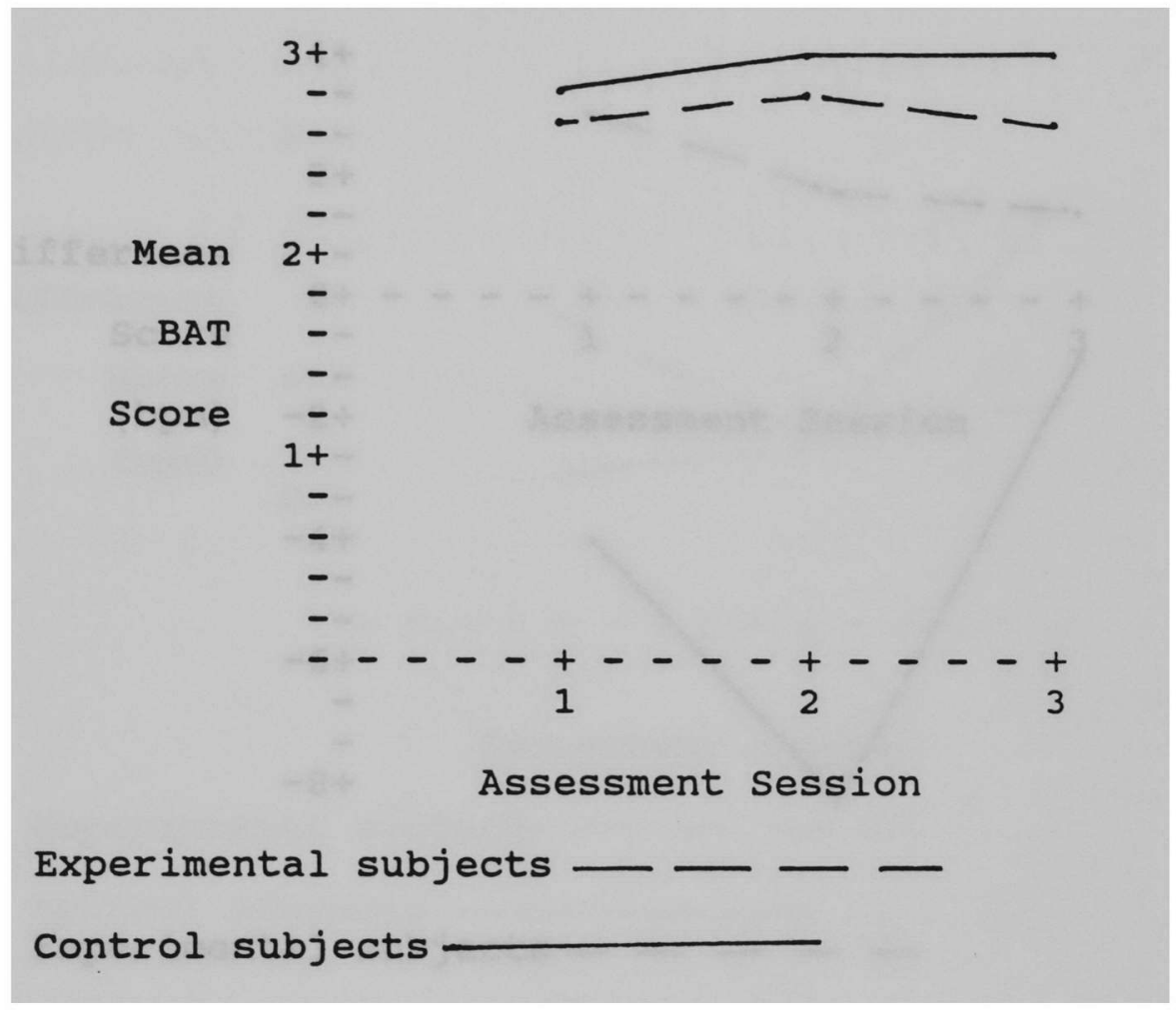


Figure 5

Difference Scores of Experimental and control subjects Across the Three Assessment Sessions

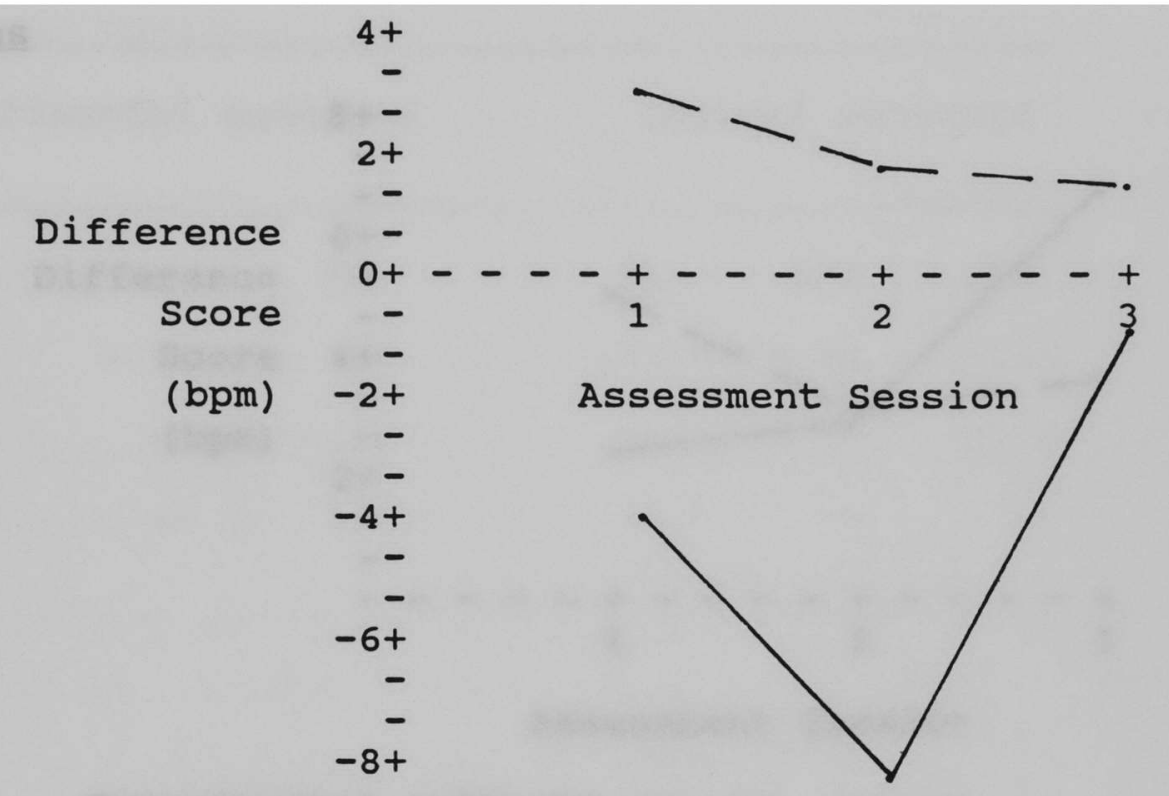

Experimental subjects - - - - Control subjects 
Figure 6

Difference Scores of Experimental and control subjects

(Excluding Subject Pair \#2) Across the Three Assessment

Sessions

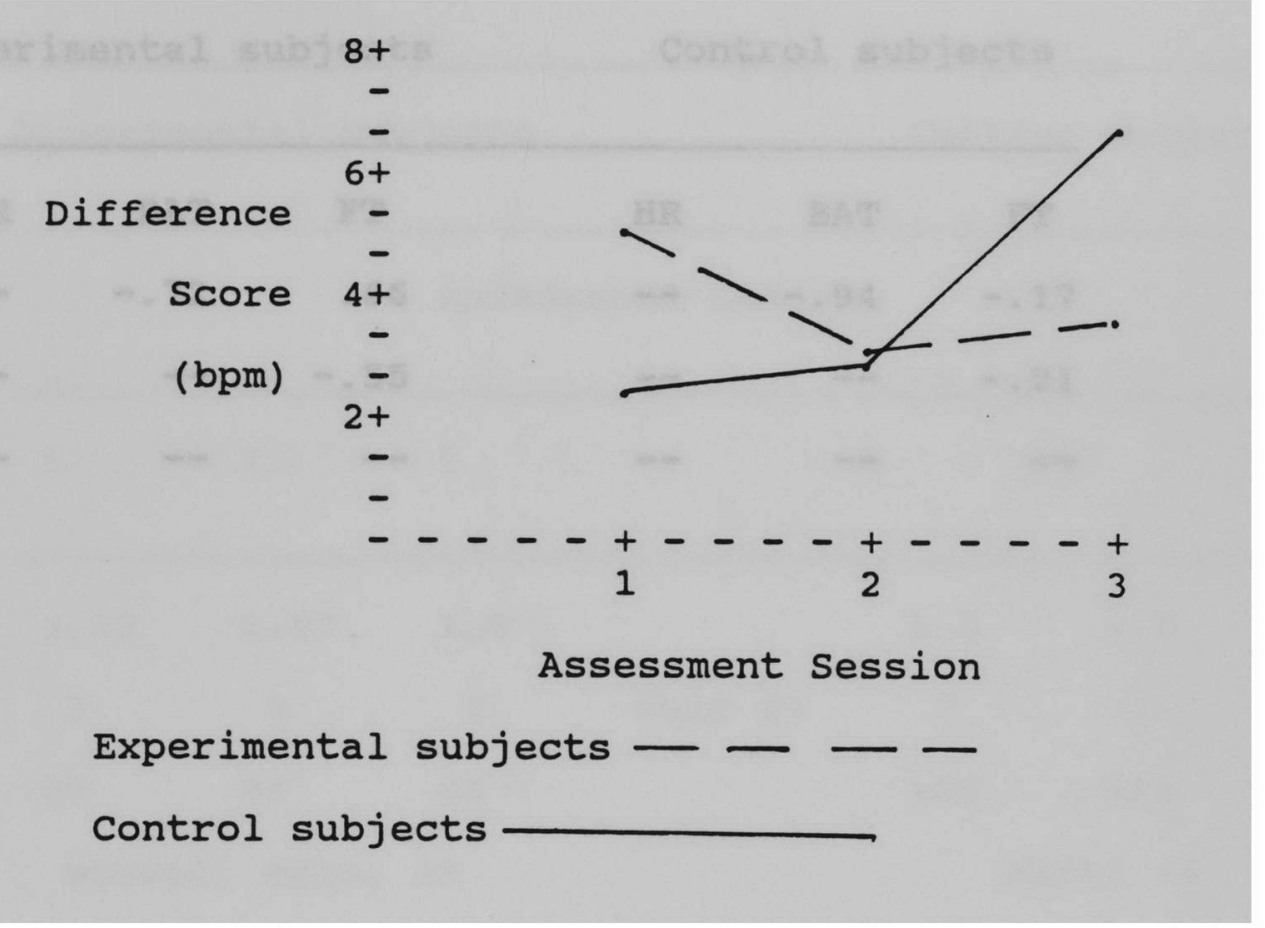


Table 2

Correlations Among the Three Response Components for

Experimental and control subjects

Experimental subjects Control subjects

\begin{tabular}{lrrrrrr}
\hline & HR & BAT & FT & HR & BAT & FT \\
HR & -- & -.72 & .66 & -- & -.94 & -.17 \\
BAT & -- & -- & -.55 & -- & -- & -.21 \\
FT & -- & -- & -- & -- & -- & --
\end{tabular}

59 
Table 3

Fear Thermometer, BAT and Heart Rate Scores for the

Experimental and Control Subjects Across the Three

\section{Assessment Sessions}

Experimental subjects

Control subjects

Assessment Session

\begin{tabular}{lllllll}
\hline 1 & 2 & 3 & 1 & 2 & 3
\end{tabular}

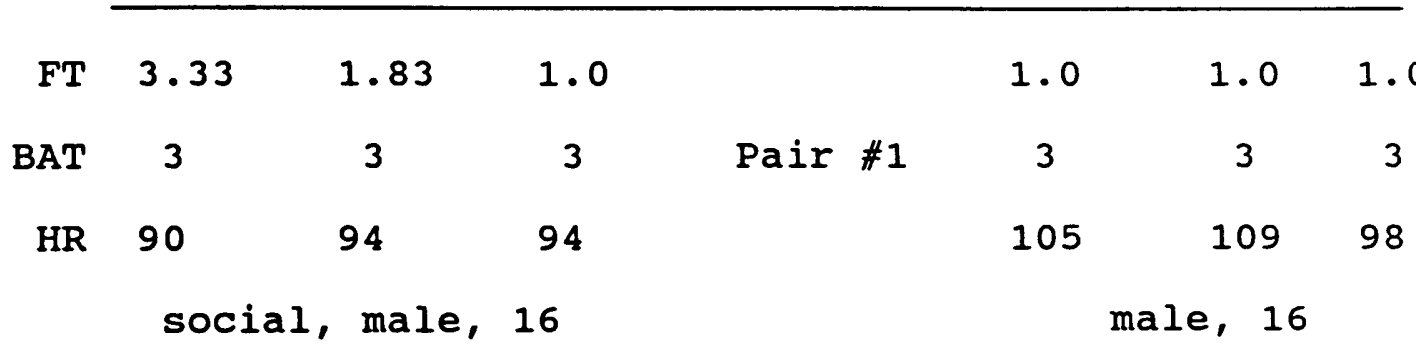

$\begin{array}{lllllll}\text { FT } & 2.83 & 2.33 & 3.0 & 1.0 & 1.0 & 1.0\end{array}$

$\begin{array}{cccccccc}\text { BAT } & 2 & 2 & 2 & \text { Pair \#2 } & 2 & 3 & 3 \\ \text { HR } & 99 & 106 & 112 & & 132 & 155 & 136 \\ & \text { height, male, } 16 & & & & \text { male, } 16\end{array}$

\begin{tabular}{cccccccc}
\hline FT & 4.0 & 4.17 & 4.0 & & 1.67 & 1.67 & 1.0 \\
BAT & 2 & 3 & 2 & Pair \#3 & 3 & 3 & 3 \\
HR & 126 & 118 & 113 & & 79 & 104 & 99 \\
& \multicolumn{2}{c}{ dog, female, 7} & & & female, 8
\end{tabular}


Table 3 (continued)

\section{Assessment Session}

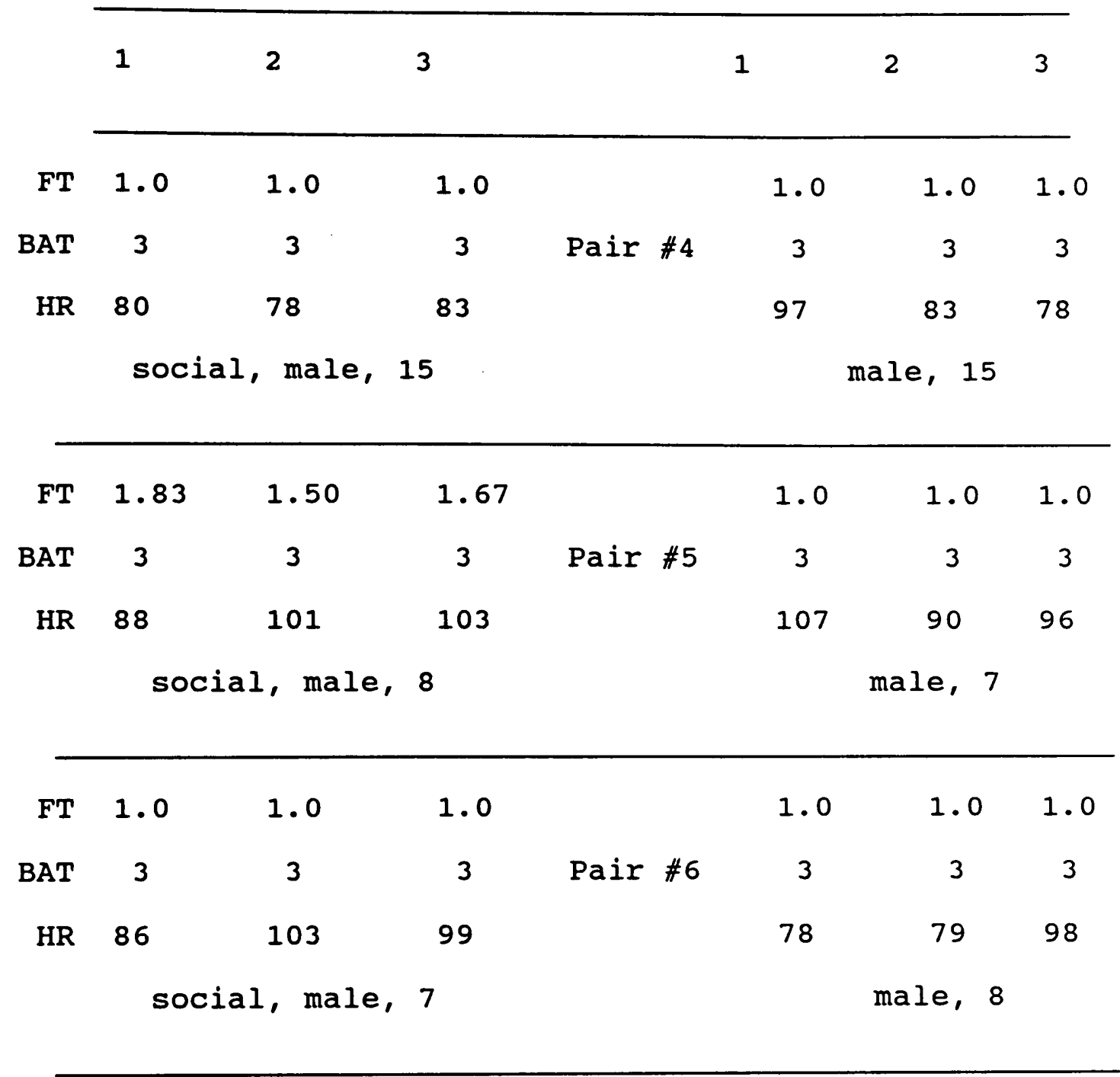


Table 4

Test-Retest Reliability coefficients of the Three Heart Rate Scores for the Experimental and control subjects

Experimental subjects Control subjects

HR \#1 HR \#2 HR \#3 $\quad$ HR \#1 $\quad$ HR \#2 HR \#3

$\begin{array}{lcccccc}\text { HR \#1 } & -- & .83 & .77 & -- & .77 & .65 \\ \text { HR \#2 } & -- & -- & .94 & -- & -- & .91 \\ \text { HR \#3 } & -- & -- & -- & -- & -- & --\end{array}$


Table 5

Test-Retest Reliability coefficients of the Three Fear Thermometer scores for the Experimental and control subjects

Experimental subjects

Control subjects

$\begin{array}{lcccccc} & \text { FT } 1 & \text { FT } 2 & \text { FT } 3 & \text { FT } 1 & \text { FT 2 } & \text { FT } 3 \\ \text { FT \#1 } & -- & .88 & .71 & -1.0 * & .98 * \\ \text { FT \#2 } & -- & -- & .92 & -1 & .98 * \\ \text { FT \#3 } & -- & -- & -- & -- & -- \\ \text { Note. } * \text { p }<.05 . & \end{array}$


Table 6

Test-Retest Reliability Coefficients of the Three BAT Scores for the Experimental and control subjects

$$
\text { Experimental subjects Control subjects }
$$

\begin{tabular}{llllll}
\hline BAT 1 & BAT 2 & BAT 3 & BAT 1 & BAT 2 & BAT 3
\end{tabular}

$\begin{array}{lllllll}\text { BAT } 1 & -- & .63 & 1.0 * & -- & .99 * & .99 * \\ \text { BAT } 2 & -- & -- & .63 & -- & -- & 1.0 * \\ \text { BAT } 3 & -- & -- & -- & -- & -- & --\end{array}$

Note. * $p<.05$. 


\section{References}

Abelson, J.L., \& Curtis, G.C. (1989). Cardiac and neuroendocrine responses to exposure therapy in height phobics: Desynchrony within the "physiological response system." Behavior Research and Therapy, 27, 561-567. Barlow, D.H., Mavissakalian, M.R., \& Schofield, L.D. (1980). Patterns of desynchrony in agoraphobia: A preliminary report. Behavior Research and Therapy, 18, 441-448. Barrios, B.A., Hartmann, D.P., \& Shigetomi, C. (1981). Fears and anxieties in children. In E.J. Mash \& L.G. Terdal (Eds.), Behavioral Assessment of Childhood Disorders, (pp. 259-304). New York: Guilford Press.

Beidel, D.C. (1988). Psychophysiological assessment of anxious emotional states in children. Journal of Abnormal Psychology, 97, 80-82.

Beidel, D.C. (1989). Assessing anxious emotion: A review of psychophysiological assessment in children. Clinical Psychology Review, 9, 717-736. Beidel, D.C., Turner, S.M., \& Dancu, C.V. (1985). Physiological, cognitive and behavioral aspects of social anxiety. Behavior Research and Therapy, 23, 109-117. Burdick, J.A. (1978). A review of heart-rate variability and evaluation. Perceptual and Motor Skills, 47, 95-105. 
Craske, M.G., Sanderson, W.C., \& Barlow, D.H. (1987). How do desynchronous response systems relate to the treatment of agoraphobia: A follow-up evaluation. Behavior Research and Therapy, 25, 117-122.

Grey, S., Sartory, G., \& Rachman, S. (1979). Synchronous and desynchronous changes during fear reduction. Behavior Research and Therapy, 17, 137-147.

Hodgson, R., \& Rachman, S. (1974). Desynchrony in measures of fear. Behavior Research and Therapy, 12, 319-326. Holden, A.E., Jr., \& Barlow, D.H. (1986). Heart rate and heart rate variability recorded in vivo in agoraphobics and nonphobics. Behavior Therapy, 17, 26-42.

Hugdahl, K. (1981). The three-systems model of fear and emotion-A critical examination. Behavior Research and Therapy, 19, 75-85.

Lang, P.J. (1977) . The psychophysiology of anxiety. In H. Akiskal (Ed.), Psychiatric Diagnosis: Exploration of Biological Criteria. New York: Spectrum. Marzillier, J.S., Carroll, D., \& Newland, J.R. (1979). Selfreport and physiological changes accompanying repeated imagining of a phobic scene. Behavior Research and Therapy, 17, 71-77.

Nesse, R.M., Curtis, G.C., Thyer, B.A., McCann, D.S., HuberSmith, M.J., \& Knopf, R.F. (1985). Endocrine and cardiovascular responses during phobic anxiety. Psychosomatic Medicine, 47, 320-332. 
Ollendick, T.H., \& Francis, G. (1988). Behavioral assessment and treatment of childhood phobias. Behavior Modification, 12, 165-204.

Ray, W.J., \& Raczynski, J.M. (1981). Psychophysiological assessment. In M. Hersen \& A.S. Bellack (Eds.), Behavioral Assessment: A Practical Handbook, (pp.175211). New York: Pergamon Press.

Silverman, W.K., \& Eisen, A.R. (in press). overanxious disorder in children. In R.T. Ammerman \& M. Hersen (Eds.), Handbook of Behavior Therapy with Children and Adults: A Developmental Perspective. New York: Pergamon Press.

Silverman, W.K., \& Eisen, A.R. (1992). Age differences in the reliability of parent and child reports of child anxious symptomatology using a structured interview. Journal of the American Academy of Child and Adolescent Psychiatry, 31, 117-124.

Silverman, W.K., \& Nelles, W.B. (1988). The anxiety disorders interview schedule for children. Journal of the American Academy of Child and Adolescent Psychiatry, 27, $772-778$

Silverman, W.K., \& Nelles, W.B. (1990). Simple phobia in childhood. In M. Hersen \& C.G. Last (Eds.), Handbook of Child and Adult Psychopathology: A Longitudinal Perspective, (pp. 183-196). New York: Pergamon Press. 
Watson, J.P., Gaind, R., \& Marks, I.M. (1972). Physiological habituation to continuous phobic stimulation. Behavior Research and Therapy, 10, 269-278. 
Appendix

\section{Derivation of the Composite Diagnosis}

Upon determination of both the child and parent diagnoses, the composite diagnosis is derived as follows: 1) If the child or parent interview provided a particular diagnosis with a severity rating by the interviewer of 4 or more the child received this diagnosis; 2 ) if both the child and parent interviews identified a diagnosis with any severity rating, the child recieved the diagnosis; 3 ) if only one interview provided a particular diagnosis with a severity rating from 0 to 3 the child did not receive that diagnosis. 